\title{
Neo Automatic Code (NAC) To Improve Return Of Spontaneus Circulation (ROSC) In Hospital Cardiac Arrest (IHCA) Patients
}

\author{
Rendi Editya Darmawan ${ }^{1}$ Untung Sujianto $^{2}$, Nana Rochana ${ }^{3}$ \\ ${ }^{1}$ Department of Nursing, Poltekkes Kemenkes Surakarta \\ ${ }^{2,3}$ Department of Nursing, Faculty of Medicine, Diponegoro University, Indonesia \\ Corresponding author: Rendi Editya Darmawan; Jalan Letjen Sutoyo, Mojosongo, Surakarta; \\ +6285354557665; ndik_ners@yahoo.com
}

\begin{abstract}
Background : a higher rate of recommended chest compression is needed for neo automatic code (NAC)-guided cardio pulmonary resuscitations (CPR) to obtain highquality chest compressions. High-quality chest compressions could improve ROSC.

Pupose: the study aim to analyze the effects of CPR using NAC on the ROSC in hospital cardiac arrest in Indonesia.

Methods: this study used a quantitative, post-test quasi-experimental design with a control group. The samples were 74 cardiac arrest patients in two hospitals in Surakarta and Klaten, Indonesia, who were selected using a purposive sampling technique. The data were analyzed by the Mann-Whitney test.

Results: the incidence of ROSC in the control group was 30\%, and in the treatment group was $35 \%$. The result of statistical analysis showed that there were differences in the ROSC in the intervention and control group with a p-value of 0.003 .

Conclusion: NAC assissted cardiopulmonary resuscitations increased ROSC. It is recommended that Code Blue Teams should use NAC to improve the quality of chest compressions for the better result of ROSC.
\end{abstract}

Keywords:

Cardiac arrest; chest compression; ROSC; CPR.

\section{BACKGROUND}

Early, high-quality cardiopulmonary resuscitation (CPR) is the key to increasing the likelihood of successful resuscita- tion in cardiac arrest (Ateyyah, Cady, Poltrock, \& Pirrallo, 2014). There are an estimated 200,000 in-hospital cardiac arrests (IHCA) each year in the U.S (Chan, 2015). In-hospital cardiac arrest (IHCA) is a catastrophic complication for patients while admitted in a medical institution. The outcome of IHCA remains poor, and understanding of the prognostic factors for survival outcome after IHCA is lacking, specifically in an oriental population (Chen, Chiu, Tang, Lin, \& Lee, 2016). IHCA patients tend to be sicker, with increased comorbidities, as well as demonstrating a higher rate of non- shockable rhythms pulseless electrical activity (PEA) or asystole (Daya, Schmicker, May, \& Morrison, 2015). 
Code blue tim in Indonesia had difficulty maintaining chest compression speed. This problem can be overcome with Neo Automatic Code (NAC). NAC is an android based application tool to maintaining chest compressions speed on 100 rates per minute, so the helper just follows sound that is released from cellphone and compresses the chest. Most Indonesians have an Andorid-based cellphone so this application is easy to carry and operate (Darmawan, Sujianto, \& Rochana, 2018).

According to Darmawan (2018) study report that the mean of accuracy of compression depth in the group did not use NAC was $68.10 \pm 17.60 \%$, and in the group use NAC was $83 \pm 6.04 \%$. CPR use NAC can improve accuracy of compression depth (Darmawan, Sudjianto, \& Rochana, 2018). Appropriate speed of chest compressions increases cardiac recoil and maximal pumped blood. This situation makes the heart rhythm return spontaneously (Perki, 2015).

The spontaneous return of heart rhythm is called return of spontaneous circulation (ROSC). ROSC is characterized by reduced pulse, measured blood pressure, increased PETCO2 (> $40 \mathrm{mmHg}$ ), and return of arterial pressure waves with intra-arterial monitor in post CA patients (AHA, 2015). Grunau et al. reported the faster the ROSC time, make improve amount of patients survived from the CA. Patients who survived increased when the ROSC appeared less than 8 minutes (Grunau et al., 2016).

\section{OBJECTIVE}

This study aim to analyze the effects of CPR using NAC on the ROSC in hospital cardiac arrest in Indonesia.

\section{METHODS}

The number of patients who had ROSC signed by the presence of pulses in a carotid artery would be recorded when the time to check the pulse has arrived. The data were analyzed by the the Mann-Whitney test. Inclusions criteria for samples were that patient were indicated have cardiac arrest, and patient do not have sign to do not resusitation. This study has ethical clearence from The Health Research Ethics Committee of Faculty of Medicine, University of Diponegoro with ethical clearance number of 176 / EC / FK RSDK / IV / 2017.

\section{RESULTS}

The total of 74 cases met the inclusion criteria, and complete data. Demographic characteristics for the study population were stratified by group as can be seen from table 1 .

Table 1. Demographicss and study characteristics stratified by group

\begin{tabular}{ccccc}
\hline Category & $\begin{array}{c}\text { Cases } \\
\mathrm{N}=37\end{array}$ & $\begin{array}{c}\text { Control } \\
\mathrm{N}=37\end{array}$ & $\mathrm{CI} / 95 \%$ & OR \\
\hline Age & & & & \\
18-40 years & $5(14 \%)$ & $6(16 \%)$ & $0,07-1,23$ & 0,3 \\
41-60 years & $19(51 \%)$ & $17(46 \%)$ & $0,52-1,35$ & 0,15 \\
$>60$ years & $13(35 \%)$ & $14(38 \%)$ & $1,10-1,56$ & 0,20 \\
Gender & $11(30 \%)$ & $17(46 \%)$ & $0,58-3,52$ & 1,37 \\
Male & $26(70 \%)$ & $20(54 \%)$ & & \\
Female & & & & \\
\hline
\end{tabular}




\begin{tabular}{ccccc}
\hline Category & $\begin{array}{c}\text { Cases } \\
\mathrm{N}=37\end{array}$ & $\begin{array}{c}\text { Control } \\
\mathrm{N}=37\end{array}$ & $\mathrm{CI} / 95 \%$ & OR \\
& & & & \\
\hline $\begin{array}{c}\text { Hearth rhythm } \\
\text { Shockable }\end{array}$ & $0(0 \%)$ & $5(14 \%)$ & & \\
Unshockable & $37(100 \%)$ & $32(86 \%)$ & $0,26-3,36$ & 0,95 \\
Main illness & & & & \\
$\quad$ Cardiact & $5(14 \%)$ & $8(21 \%)$ & 0,831 & 1,52 \\
Non Cardiact & $32(86 \%)$ & $29(79 \%)$ & 1,92 & \\
\hline
\end{tabular}

The result showed that the majority of respondents in intervention and control group were 41-60 years and female. The most common rhythm in intervention and control group shortly before cardiac arrest was unshockable rhythm which were 37 respondents $(100 \%)$ and 32 respondents $(86 \%)$ respectively. The leading cause of cardiac arrest patients in intervention group was non cardiac $(n=32,86 \%)$ followed by cardiac $(n=5$, $14 \%)$ and in control group was non cardiac $(n=29,79 \%)$ followed by cardiac $(n=8$, $21 \%)$.

Table 2. Incidence of ROSC

\begin{tabular}{lccccc}
\hline Group & ROSC & Not ROSC & CI/95\% & OR & P Value \\
\hline Intervention & 13 & $24(65 \%)$ & $0,68-1,43$ & 0,2 & 0,03 \\
& $(35 \%)$ & & & & \\
Control & 11 & $26(70 \%)$ & $0,37-1,85$ & 0,5 & \\
& $(30 \%)$ & & & & \\
\hline
\end{tabular}

The result showed that ROSC in the intervention group was higher than in the control group, $35 \%$ and $30 \%$ respectively as can be seen from table 2 . Table 2 show the result of stastical analysis were $\mathrm{p}$ value of 0,03 meaning that there were differences in the ROSC in the case and control groups. There was a significant effect from NAC to improve ROSC in IHCA patient.

\section{DISCUSSION}

According to result of this study were age $>40$ years old, and unshockable rythm are the most category patient, It,s like OPALS study. Overall IHCA survival for women was lower than for men in the OPALS study. Factors related to the sex differences in survival (rates of bystander CPR and shockable rhythms) may be modifiable. The probability of survival differed across age for men and women in a nonlinear fashion. This differential influence of age on survival for men and women should be considered in future studies evaluating survival by sex in IHCA population (Safdar et al., 2014).

The result of statistical analysis showed that there were differences in the incidence of ROSC in the intervention and control group with value 0,03 (p-value<0.05). One of factors can make it different is absence speed regulator for arrange compression rates in control group makes differences in the accuracy of compression depth. 
Control group did not using NAC. Absence speed regulator for arrange compression rates makes faster of chest compression rates than using NAC. Increase of chest compression rates causing increase fatigue among the control group, which consequently resulted in a decrease in the accuracy of compression depth (Field, Soar, Davies, Akhtar, \& Perkins, 2011; Gauna, González-otero, Ruiz, \& Russell, 2016; Hasegawa, Daikoku, Saito, \& Saito, 2014; Idris et al., 2012; Monsieurs et al., 2012).

Field et al (Field et al., 2011) showing that faster compressions lead to reduced compression depth. Monsieurs et al (Monsieurs et al., 2012) showing high compression rates were common and may be explained by stress or by the inability of rescuers to assess and control the compression rate.

The compression rate given per minute during CPR is a major determinant of the condition of ROSC (return of spontaneous circulation) and survival with good neurological function. The actual amount of chest compression given per minute is determined by the rate of chest compression and the amount and duration of the disturbance in compression (for example, to open the airway, give artificial breath, allow analysis of AED). In most studies, more compression is associated with higher survival rates, and less compression is associated with lower survival rates. Applying proper chest compression requires emphasis not only on adequate compression rate, but also on efforts to minimize disruption to this important component of CPR (AHA, 2015).

NAC can minimize the interuption, caused by helper changes, besides it can also increase chest recoil because a stable rate $100 \mathrm{x} /$ minute is proven to increase chest recoil, thus increasing the patient's blood flow cardiac arrest to the heart, brain, lungs and other vital organs thus increasing the potential of the ROSC. NAC is also equipped with a timed ventilation code, so the helper will not provide ventilation with excessive time (Darmawan, Yahya Adi, \& Ernawati, 2016). Limitations of this study were that core diseases in this study were heterogen.

\section{CONCLUSION}

There were effects of Neo automatic code assissted CPR on ROSC. Neo automatic code could increase ROSC. Rescuer of cardiac arrest patient should have had knowledge about factors improving ROSC such as response time to help CA patients, the cause of CA patient, and the quality of chest compressions.

\section{ACKNOWLEDGMENTS:}

Acknowledgement of the author to the lecturers of University of Diponegoro and Poltekkes Surakarta who have motivated and provided solutive direction. Thanks to Ns Rakhma Anindhita, S. Kep, who helped produce Neo Automatic codes, as well as an informatics team that has helped create neo automatic code applications. The code blue team of hospitals in Surakarta and Klaten, as well as the other parties which contribution to the research.

\section{REFERENCES}

AHA. (2015). Highlights of the 2015 American Heart Association guidelines update for CPR and ECC. In American Heart Association. 
Ateyyah, K. A., Cady, C. E., Poltrock, J. T., \& Pirrallo, R. G. (2014). A novel use of a metronome in dispatcher assisted cardiopulmonary resuscitation. Prehospital Emergency Care : Official Journal of the National Association of EMS Physicians and the National Association of State EMS Directors, 19(1), 131-134. https://doi.org/10.3109/10903127.2014.936632

Chan, P. (2015). Public health burden of in-hospital cardiac arrest. Paper Commissioned by the Committee on the Treatment of Cardiac Arrest: Current Status and Future Directions. Retrieved from http://www.iom.edu/ /media/Files/Report Files/2015/GWTG.pdf

Chen, C., Chiu, P., Tang, C., Lin, Y., \& Lee, Y. (2016). Prognostic factors for survival outcome after in-hospital cardiac arrest: An observational study of the oriental population in Taiwan. Journal of the Chinese Medical Association, 79(1), 11-16. https://doi.org/10.1016/j.jcma.2015.07.011

Darmawan, R. E., Sujianto, U., \& Rochana, N. (2018). Effects of Neo Automatic Code on the Accuracy of Chest Compression Depths in Cardiac Arrest Patients. Hiroshima J. Med. Sci, 67(024), 161-165.

Darmawan, Yahya Adi, \& Ernawati. (2016). Automatic code red: meningkatkan efisiensi kompresi dada. Proceedings Meningkatkan Kualitas Tenaga Kesehatan Melalui Penelitian, Pengabdian Masyarakat, Dan Publikasi Ilmiah, 17-18.

Daya, M. R., Schmicker, R. H., May, S., \& Morrison, L. J. (2015). Current burden of cardiac arrest in the United States: report from the resuscitation outcomes consortium. Paper Commissioned by the Committee on the Treatment of Cardiac Arrest: Current Status and Future Directions. Retrieved from http://www.iom.edu/ /media/Files/Report Files/2015/ROC.pdf

Field, Soar, Davies, Akhtar, \& Perkins. (2011). The impact of chest compression rates on quality of chest compressions - a manikin study. Resuscitation, 83(3), 360-364. https://doi.org/http://dx.doi.org/10.1016/j.resuscitation.2011.07.012.

Gauna, S. R. De, González-otero, D. M., Ruiz, J., \& Russell, J. K. (2016). Feedback on the rate and depth of chest compressions during cardiopulmonary resuscitation using only accelerometers. Plos One, 11(3), 1-17. https://doi.org/10.1371/journal.pone.0150139

Grunau, B., Reynolds, J., Scheuermeyer, F., Stenstom, R., Stub, D., Pennington, S., ... Christenson, J. (2016). Relationship between time to ROSC and survival in out of hospital cardiac arrest ECPR candidates: when is the best time to consider transport to hospital? Prehospital Emergency Care: Official Journal of the National Association of EMS Physicians and the National Association of State EMS Directors, 20(5), 615-622. https://doi.org/10.3109/10903127.2016.1149652

Hasegawa, T., Daikoku, R., Saito, S., \& Saito, Y. (2014). Relationship between weight of rescuer and quality of chest compression during cardiopulmonary resuscitation. 
Physiological Anthropology, 33(16), 1-7.

Idris, A. H., Guffey, D., Aufderheide, T. P., Brown, S., Morrison, L. J., Nichols, P., ... Nichol, G. (2012). Relationship between chest compression rates and outcomes from cardiac arrest. Circulation, 125(24), 3004-3012. https://doi.org/10.1161/CIRCULATIONAHA.111.059535

Monsieurs, K. G., De Regge, M., Vansteelandt, K., De Smet, J., Annaert, E., Lemoyne, S., ... Calle, P. a. (2012). Excessive chest compression rate is associated with insufficient compression depth in prehospital cardiac arrest. Resuscitation, 83(11), 1319-1323. https://doi.org/10.1016/j.resuscitation.2012.07.015

Perki. (2015). Henti jantung. Retrieved from Heart.org website: http://www.inaheart.org/education_for_patient/2015/5/7/henti_jantung

Safdar, B., Stolz, U., Stiell, I. G., Cone, D. C., Bobrow, B. J., DeBoehr, M., ... Spaite, D. W. (2014). Differential survival for men and women from out-of-hospital cardiac arrest varies by age: results from the OPALS study. Academic Emergency Medicine: Official Journal of the Society for Academic Emergency Medicine, 21(12), 1503-1511. https://doi.org/10.1111/acem.12540 